\title{
BMJ Open Maternal healthcare utilsation and complete childhood vaccination in sub- Saharan Africa: a cross-sectional study of 29 nationally representative surveys
}

\author{
Eugene Budu, ${ }^{1}$ Bright Opoku Ahinkorah (D) , ${ }^{2}$ Richard Gyan Aboagye, ${ }^{3}$ \\ Ebenezer Kwesi Armah-Ansah, ${ }^{1}$ Abdul-Aziz Seidu (D) , ${ }^{1,4}$ Collins Adu, ${ }^{5}$ \\ Edward Kwabena Ameyaw, ${ }^{2}$ Sanni Yaya (i) ${ }^{6,7}$
}

To cite: Budu E, Ahinkorah B0, Aboagye RG, et al. Maternal healthcare utilsation and complete childhood vaccination in sub-Saharan Africa: a cross-sectional study of 29 nationally representative surveys. BMJ Open 2021;11:e045992. doi:10.1136/ bmjopen-2020-045992

- Prepublication history and additional supplemental material for this paper are available online. To view these files, please visit the journal online (http://dx.doi.org/10.1136/ bmjopen-2020-045992).

Received 18 0ctober 2020 Revised 27 March 2021 Accepted 29 March 2021

Check for updates

(C) Author(s) (or their employer(s)) 2021. Re-use permitted under CC BY-NC. No commercial re-use. See rights and permissions. Published by BMJ.

For numbered affiliations see end of article.

Correspondence to

Dr Sanni Yaya;

sanni.yaya@u0ttawa.ca

\section{ABSTRACT}

Objective The objective of the study was to examine the association between maternal healthcare utilisation and complete childhood vaccination in sub-Saharan Africa. Design Our study was a cross-sectional study that used pooled data from 29 countries in sub-Saharan Africa. Participants A total of 60964 mothers of children aged 11-23 months were included in the study.

Outcome variables The main outcome variable was complete childhood vaccination. The explanatory variables were number of antenatal care (ANC) visits, assistance during delivery and postnatal care (PNC).

Results The average prevalence of complete childhood vaccination was $85.6 \%$, ranging from $67.0 \%$ in Ethiopia to $98.5 \%$ in Namibia. Our adjusted model, children whose mothers had a maximum of three ANC visits were $56 \%$ less likely to have complete vaccination, compared with those who had at least four ANC visits (adjusted $\mathrm{OR}(\mathrm{aOR})=0.44,95 \% \mathrm{Cl} 0.42$ to 0.46$)$. Children whose mothers were assisted by traditional birth attendant/ other (aOR=0.43, 95\% $\mathrm{Cl} 0.41$ to 0.56 ) had lower odds of complete vaccination. The odds of complete vaccination were lower among children whose mothers did not attend PNC clinics ( $\mathrm{aOR}=0.26,95 \% \mathrm{Cl} 0.24$ to 0.29 ) as against those whose mothers attended.

Conclusion The study found significant variations in complete childhood vaccination across countries in subSaharan Africa. Maternal healthcare utilisation (ANC visits, skilled birth delivery, PNC attendance) had significant association with complete childhood vaccination. These findings suggest that programmes, interventions and strategies aimed at improving vaccination should incorporate interventions that can enhance maternal healthcare utilisation. Such interventions can include education and sensitisation, reducing cost of maternal healthcare and encouraging male involvement in maternal healthcare service utilisation.

\section{INTRODUCTION}

Maternal healthcare and childhood vaccination are major public health issues in sub-Saharan Africa (SSA) and the international community has prioritised them by integrating them into the Sustainable

\section{Strengths and limitations of this study}

- One of the strengths of the study was the use of data from nationally representative surveys.

- The surveys employed a multistage sampling technique to recruit the study participants, making the results generalisable to all children aged 11-23 months in sub-Saharan Africa.

- One key limitation of the study is that the surveys were cross-sectional in nature and this makes it difficult for the study to establish a causal relationship.

- Use of verbal responses to ascertain information on childhood vaccination could be prone to potential recall bias.

Development Goals (SDGs). ${ }^{1-3}$ Maternal healthcare services are regarded as essential because they are not only required to improve and promote women's reproductive health but also needed to reduce maternal and child mortality. ${ }^{4}$ Effective utilisation of maternal healthcare services has led to a significant progress in maternal health, as evident in the reduction of maternal mortality ratio from 342 to 211 deaths per 100000 live births from 2000 to 2017 worldwide. ${ }^{5}$ Despite the decline, more than 500000 women have died from causes related to pregnancy and childbirth, with high vulnerabilities among women in SSA. ${ }^{67}$

Target 2 of SDG 3 highlights the need to improve child health and survival rates, and this has enhanced significant changes in public and private investments, with the aim of promoting access to affordable programmes that improve the health of children, particularly in vaccination. ${ }^{8}$ Globally, in 2019, about 116 million infants received three doses of diphtheria-tetanus-pertussis (DTP3) vaccine, protecting them against infectious diseases that can cause serious illness and 
disability or can be fatal. ${ }^{9} 10$ This contributed to the prevention of at least 2.5 million neonatal and under-5 mortality globally. ${ }^{11-13}$

Despite the global improvement in child health due to vaccination, SSA had the highest neonatal mortality rate in 2019 at 27 deaths per 1000 live births, followed by Central and Southern Asia with 24 deaths per 1000 live births. ${ }^{13}$ These mortalities can be prevented if women use essential components of basic maternal health services, such as antenatal care (ANC) and skilled healthcare personnel during delivery, and receive available relevant postpartum health services and emergency obstetric care. $^{14-16}$

A recent systematic review and meta-analysis found that ANC visits decreased the risk of neonatal mortality by $34 \%$ in SSA, ${ }^{17}$ and newborns delivered with skilled birth attendance were $16 \%$ less likely to die within 2-27 days than those without skilled birth attendance. ${ }^{18}$ In terms of postnatal care (PNC), studies have shown that approximately two-thirds of neonatal mortality in SSA could be prevented using existing programmes on maternal and child health, including PNC. ${ }^{190}$

Although childhood vaccination has yielded some positive outcomes worldwide, there is low coverage in SSA and consequently poor child health outcomes. ${ }^{21}{ }^{22}$ Childhood vaccination forms an important aspect of maternal healthcare utilisation. Therefore, it is recommended that vaccination should begin immediately after childbirth within a specified period of time. ${ }^{23}$ However, whether women in SSA who use maternal healthcare services are more likely to vaccinate their children compared with those who do not use maternal healthcare services is unknown. Therefore, we examined the association between maternal healthcare service utilisation and complete childhood vaccination in SSA.

\section{METHODS}

\section{Data source}

The study used data from the Demographic and Health Surveys (DHS) of 29 countries in SSA. Specifically, data from birth recode files that contain information on all births of women aged 15-49 were used. The DHS is a nationally representative survey that is carried out in more than 85 low-income and middle-income countries globally. The survey covers a range of significant maternal and child health indicators, such as childhood vaccination and maternal healthcare utilisation. ${ }^{24}$

\section{Study design}

The DHS uses a repeated cross-sectional research design. This research design was used because complete coverage of the population was impossible, and it addresses the survey population in a short period of time and produces comparable and equal valid results.

\section{Inclusion and exclusion criteria}

In terms of the selection of the surveys, the inclusion criteria were those that were published between January
2010 and December 2019 and had information on maternal healthcare utilisation and childhood vaccination. Hence, surveys that were published before 2010 and did not have information on maternal healthcare utilisation and childhood vaccination were excluded. For the selection of respondents, the inclusion criteria were children less than 23 months whose mothers had complete information on maternal healthcare utilisation and childhood vaccination. Hence, children more than 23 months whose mothers did not have complete information on maternal healthcare utilisation and childhood vaccination were excluded.

\section{Sample size and sampling procedure}

A two-stage stratified sampling technique is employed in each survey in order to ensure national representativeness. Details of the sampling process that guide the DHS can be found in the study by Aliaga and Ren. ${ }^{25} \mathrm{~A}$ sample size of 60964 children under 5 were included in this study. Table 1 provides the details of the surveys and the sample employed in this study. We relied on the Strengthening the Reporting of Observational Studies in Epidemiology statement (online supplemental file 1) in writing the manuscript. ${ }^{26}$ The data set is freely available for download at https://dhsprogram.com/data/available-datasets.cfm.

\section{Definition of variables \\ Dependent variable}

The dependent variable in this study is complete vaccination, also called full vaccination. Following the WHO recommendations on routine vaccination ${ }^{27}$ and based on previous studies, ${ }^{28}{ }^{29}$ we defined complete childhood vaccination as a child who has received one dose of BCG, three doses of pentavalent pneumococcal conjugate, oral polio vaccines, two doses of rotavirus and one dose of measles vaccine. Children who did not get all these vaccines were considered as those with incomplete vaccination. Complete childhood vaccination was coded as 1 and incomplete as $0 .{ }^{2829}$

\section{Independent variables}

The study used maternal healthcare service utilisation as the main independent variable. These variables included ANC attendance, assistance during delivery and PNC attendance. With ANC, women were asked about the number of antenatal visits they made during their recent pregnancy. Utilisation of ANC visits was coded as $<4$ visits and $\geq 4$ visits. Assistance during delivery was derived from the question 'Who assisted [NAME] during delivery?' The response to this question was categorised into 'Traditional Birth Attendant (TBA)/Others' and 'Skilled Birth Attendant (SBA)/Health professionals'. PNC attendance was derived from the question 'Did [NAME] go for postnatal checks within 2 months?' By excluding respondents who responded 'don't know' to this question, we coded the variable as 'yes' and 'no'. 
Table 1 Country, year of survey, population and samples

\begin{tabular}{|c|c|c|c|c|c|}
\hline Country & Year of survey & Population & Sample* & Sample† & Sample \\
\hline Angola & 2015-2016 & 42002 & 3043 & 3028 & 2567 \\
\hline Benin & 2018 & 45853 & 5423 & 5092 & 4938 \\
\hline Burundi & 2016-2017 & 45419 & 2591 & 2590 & 2591 \\
\hline Cameroon & 2018 & 42312 & 2441 & 2441 & 849 \\
\hline Comoros & 2012 & 11497 & 1259 & 1247 & 1165 \\
\hline Congo & 2013 & 31948 & 2067 & 2056 & 1744 \\
\hline $\begin{array}{l}\text { Democratic Republic of } \\
\text { Congo }\end{array}$ & 2013-2014 & 59276 & 3704 & 3679 & 3387 \\
\hline Cote D'Ivoire & 2011-2012 & 28211 & 1575 & 1573 & 1462 \\
\hline Ghana & 2014 & 23118 & 1218 & 1218 & 1159 \\
\hline Guinea & 2018 & 28887 & 1525 & 1515 & 1398 \\
\hline Kenya & 2014 & 83591 & 7861 & 7690 & 3309 \\
\hline Lesotho & 2014 & 11710 & 655 & 654 & 211 \\
\hline Liberia & 2013 & 30804 & 1499 & 1475 & 1258 \\
\hline Malawi & 2015-2016 & 68074 & 2207 & 2126 & 2098 \\
\hline Mali & 2018 & 33379 & 3812 & 3805 & 3779 \\
\hline Namibia & 2013 & 18090 & 952 & 947 & 764 \\
\hline Zambia & 2018 & 38446 & 3874 & 3873 & 3643 \\
\hline Zimbabwe & 2015 & 20791 & 2240 & 2238 & 2277 \\
\hline Total & & 1211352 & 76319 & 73689 & 60964 \\
\hline
\end{tabular}

*Children less than 23 months.

†Children who received vaccination.

‡Children with complete cases.

\section{Control variables}

Fourteen variables were considered in this study as covariates and were broadly grouped into child and maternal related variables as well as community-level variables. The child and maternal related variables included size of child at birth, birth order, twin status, type of delivery, mother's age, marital status, employment status, religion, and exposure to newspaper, radio and television. The community-level factors included type of place of residence, community literacy level and community socioeconomic status. The selection of these variables was guided by theoretical relevance and practical significance with complete childhood vaccination. ${ }^{30-34}$

\section{Statistical analyses}

Using Stata V.14.0, we first computed the prevalence of complete immunisation in SSA as well as the prevalence of each component of maternal healthcare service utilisation. Next, we calculated the proportions of complete immunisation across the independent and control variables using $\mathrm{X}^{2}$ test of independence. After this, we used variance inflation factor (VIF) to check for multicollinearity and the results showed no evidence of high collinearity (mean $\mathrm{VIF}=1.30$, maximum $\mathrm{VIF}=2.09$ and minimum VIF=1.01). All variables that showed statistical significance during the $\mathrm{X}^{2}$ test were considered for the final stage of analysis that involved a multilevel logistic 
regression analysis. Five models were built for the multilevel logistic regression analysis. Model 0 was the null or empty model and showed the variance in childhood vaccination explained by the primary sampling units. This model had no explanatory variables. Model 1 had only the key independent variables (ANC attendance, assistance during delivery and PNC attendance) and showed their association with complete vaccination. In the next model (model 2), maternal and child factors were added to the first model to find their association with complete vaccination. In model 3 , community-level factors were added to model 2 to examine the associations between those variables in the model and complete vaccination. Finally, model 4 was the complete model where all the explanatory variables were included in the model to find their association with complete vaccination. The reference category for the multilevel logistic regression was the category with the least frequency. The multilevel logistic regression analysis comprised fixed effects and random effects. ${ }^{35}$ The results of the fixed effects of the model were presented as adjusted $\mathrm{OR}(\mathrm{aOR})$, while the random effects were assessed with intracluster correlation. ${ }^{36}$ Model comparison was done using the log-likelihood ratio and Akaike's information criterion (AIC) tests. The highest log-likelihood (-20 923.521) and the lowest AIC (41 919.04) were used to determine the best fit model. We applied sample weights (v005/1 000 000) for all the frequency distributions, while the svyset command in Stata was used to adjust for the complex sampling structure of the data in the regression analyses. Missing data were handled using complete cases.

\section{Patient and public involvement}

Neither patient groups nor the public were involved in this study.

\section{RESULTS}

Prevalence of maternal healthcare utilisation and complete childhood vaccination

The overall prevalence of complete childhood vaccination was $85.6 \%$, ranging from $67.0 \%$ in Ethiopia to $98.5 \%$ in Namibia. With ANC visits, Chad (32.8\%) recorded the lowest coverage, with the highest coverage in Senegal (94.7\%). From the 29 countries, the prevalence of at least four ANC visits was $56.0 \%$. Skilled birth attendance was more prevalent in Congo (97.6\%), compared with the lowest rate in Gambia (31.8\%), with an overall prevalence of $74.7 \%$. PNC attendance was $41.0 \%$ in all the countries combined. PNC prevalence ranged from $7.8 \%$ in Ethiopia to $83.3 \%$ in Zimbabwe (table 2).

\section{Prevalence of complete vaccination across maternal} healthcare utilisation and child and maternal and communitylevel factors

Table 3 shows the distribution of complete vaccinations across maternal healthcare utilisation and child and maternal and community-level factors in the SSA. The
Table 2 Prevalence of maternal healthcare utilisation and complete childhood vaccination in sub-Saharan Africa

\begin{tabular}{|c|c|c|c|c|}
\hline Country & $\begin{array}{l}\text { Complete } \\
\text { vaccination }\end{array}$ & $\begin{array}{l}\text { Four } \\
\text { or } \\
\text { more } \\
\text { ANC } \\
\text { visits }\end{array}$ & $\begin{array}{l}\text { Assisted } \\
\text { by skilled } \\
\text { birth } \\
\text { attendant } \\
\text { during } \\
\text { delivery }\end{array}$ & $\begin{array}{l}\text { Attended } \\
\text { PNC }\end{array}$ \\
\hline Angola & 74.9 & 62.7 & 77.3 & 22.1 \\
\hline Burkina Faso & 94.3 & 32.0 & 72.2 & 82.3 \\
\hline Benin & 86.3 & 53.8 & 82.9 & 19.0 \\
\hline Burundi & 98.2 & 51.5 & 90.6 & 9.2 \\
\hline $\begin{array}{l}\text { Democratic } \\
\text { Republic of } \\
\text { Congo }\end{array}$ & 80.0 & 47.3 & 88.5 & 16.5 \\
\hline Congo & 93.5 & 76.2 & 97.6 & 58.9 \\
\hline Cote D'Ivoire & 82.9 & 42.1 & 80.8 & 70.2 \\
\hline Cameroon & 71.0 & 34.5 & 67.3 & 15.7 \\
\hline Ethiopia & 67.0 & 34.0 & 47.4 & 7.8 \\
\hline Gabon & 92.7 & 78.9 & 92.8 & 54.5 \\
\hline Ghana & 95.7 & 87.3 & 75.2 & 73.2 \\
\hline Gambia & 95.3 & 75.7 & 31.8 & 73.7 \\
\hline Guinea & 72.5 & 35.1 & 59.0 & 30.5 \\
\hline Kenya & 96.6 & 55.4 & 67.3 & 64.9 \\
\hline Comoros & 85.8 & 61.6 & 88.1 & 35.0 \\
\hline Liberia & 92.1 & 80.8 & 73.1 & 68.5 \\
\hline Lesotho & 97.5 & 77.8 & 91.0 & 81.6 \\
\hline Mali & 81.8 & 46.6 & 75.9 & 26.7 \\
\hline Malawi & 97.5 & 49.4 & 92.9 & 43.2 \\
\hline Nigeria & 78.2 & 68.5 & 74.3 & 29.1 \\
\hline Namibia & 98.5 & 83.2 & 94.4 & 53.6 \\
\hline Rwanda & 97.4 & 43.6 & 85.2 & 52.4 \\
\hline Sierra Leone & 94.6 & 89.1 & 71.1 & 70.2 \\
\hline Senegal & 90.2 & 94.7 & 72.8 & 73.1 \\
\hline Chad & 62.5 & 32.8 & 37.5 & 15.6 \\
\hline Togo & 93.4 & 54.1 & 65.0 & 73.0 \\
\hline Uganda & 95.9 & 60.9 & 86.9 & 22.4 \\
\hline Zambia & 93.7 & 63.8 & 85.3 & 62.7 \\
\hline Zimbabwe & 89.5 & 74.5 & 83.5 & 83.3 \\
\hline Total & 85.6 & 56.0 & 74.7 & 41.0 \\
\hline
\end{tabular}

ANC, antenatal care; PNC, postnatal care.

results showed that $92.6 \%$ of women who had at least four ANC visits had their children completely vaccinated. The majority $(90.8 \%)$ of women with SBA had their children vaccinated. Most $(95.2 \%)$ of the women with PNC attendance vaccinated their children completely. The prevalence of complete childhood vaccination was highest among children whose size at birth was average $(86.9 \%)$, first birth order $(88.8 \%)$ and multiple twin birth status $(86.7 \%)$. Also, the prevalence of complete 
Table 3 Distribution of complete vaccination across maternal healthcare utilisation and child and maternal and community-level factors in sub-Saharan Africa

\begin{tabular}{|c|c|c|c|c|}
\hline Variables & $\begin{array}{l}\text { Weighted } \\
\mathrm{n}\end{array}$ & $\begin{array}{l}\text { Weighted } \\
\%\end{array}$ & $\begin{array}{l}\text { Complete } \\
\text { childhood } \\
\text { vaccination }\end{array}$ & P value* \\
\hline ANC attendance & & & & $<0.001$ \\
\hline$<4$ visits & 26817 & 44.0 & 76.6 & \\
\hline$\geq 4$ visits & 34147 & 56.0 & 92.6 & \\
\hline Birth assistant & & & & $<0.001$ \\
\hline $\begin{array}{l}\text { Traditional } \\
\text { Birth } \\
\text { Attendant } \\
\text { (TBA)/others }\end{array}$ & 15412 & 25.3 & 70.2 & \\
\hline $\begin{array}{l}\text { Skilled Birth } \\
\text { Attendant } \\
\text { (SBA) }\end{array}$ & 45552 & 74.7 & 90.8 & \\
\hline PNC attendance & & & & $<0.001$ \\
\hline No & 35945 & 59.0 & 78.9 & \\
\hline Yes & 25019 & 41.0 & 95.2 & \\
\hline Size of child at b & irth & & & $<0.001$ \\
\hline $\begin{array}{l}\text { Larger than } \\
\text { average }\end{array}$ & 22153 & 36.3 & 86.0 & \\
\hline Average & 28446 & 46.7 & 86.9 & \\
\hline $\begin{array}{l}\text { Smaller than } \\
\text { average }\end{array}$ & 10365 & 17.0 & 81.3 & \\
\hline Birth order & & & & $<0.001$ \\
\hline First & 12875 & 21.1 & 88.8 & \\
\hline $2-4$ & 29506 & 48.4 & 86.8 & \\
\hline $5+$ & 18583 & 30.5 & 81.4 & \\
\hline Twin status & & & & 0.211 \\
\hline Single birth & 59956 & 98.3 & 85.5 & \\
\hline Multiple birth & 1008 & 1.7 & 86.7 & \\
\hline Type of delivery & & & & $<0.001$ \\
\hline Vaginal birth & 57806 & 94.8 & 85.0 & \\
\hline $\begin{array}{l}\text { Caesarean } \\
\text { birth }\end{array}$ & 3158 & 5.2 & 95.4 & \\
\hline Mother's age & & & & $<0.001$ \\
\hline $15-19$ & 6359 & 10.4 & 82.9 & \\
\hline $20-24$ & 15214 & 25.0 & 86.3 & \\
\hline $25-29$ & 16365 & 26.8 & 85.8 & \\
\hline $30-34$ & 11869 & 19.5 & 85.8 & \\
\hline $35-39$ & 7624 & 12.5 & 85.2 & \\
\hline $40-44$ & 2882 & 4.7 & 86.2 & \\
\hline $45-49$ & 650 & 1.1 & 82.2 & \\
\hline Marital status & & & & $<0.001$ \\
\hline $\begin{array}{l}\text { Never } \\
\text { married }\end{array}$ & 4265 & 7.0 & 91.0 & \\
\hline Married & 43967 & 72.1 & 84.3 & \\
\hline Cohabiting & 9700 & 15.9 & 87.8 & \\
\hline Widowed & 473 & 0.8 & 86.2 & \\
\hline Divorced & 2560 & 4.2 & 89.5 & \\
\hline \multicolumn{4}{|c|}{ Employment status } & $<0.001$ \\
\hline
\end{tabular}

Continued
Table 3 Continued

\begin{tabular}{|c|c|c|c|c|}
\hline Variables & $\begin{array}{l}\text { Weighted } \\
\mathrm{n}\end{array}$ & $\begin{array}{l}\text { Weighted } \\
\%\end{array}$ & $\begin{array}{l}\text { Complete } \\
\text { childhood } \\
\text { vaccination }\end{array}$ & P value* \\
\hline Not working & 20089 & 33.0 & 82.3 & \\
\hline Working & 40875 & 67.0 & 87.2 & \\
\hline \multicolumn{4}{|c|}{ Frequency of reading newspaper } & $<0.001$ \\
\hline Not at all & 52601 & 86.3 & 84.1 & \\
\hline $\begin{array}{l}\text { Less than } \\
\text { once a week }\end{array}$ & 4661 & 7.6 & 94.9 & \\
\hline $\begin{array}{l}\text { At least once } \\
\text { a week }\end{array}$ & 3702 & 6.1 & 94.7 & \\
\hline \multicolumn{4}{|c|}{ Frequency of listening to radio } & $<0.001$ \\
\hline Not at all & 28343 & 46.5 & 80.0 & \\
\hline $\begin{array}{l}\text { Less than } \\
\text { once a week }\end{array}$ & 11053 & 18.1 & 89.0 & \\
\hline $\begin{array}{l}\text { At least once } \\
\text { a week }\end{array}$ & 21567 & 35.4 & 91.1 & \\
\hline \multicolumn{4}{|c|}{ Frequency of watching television } & $<0.001$ \\
\hline Not at all & 38974 & 63.9 & 82.1 & \\
\hline $\begin{array}{l}\text { Less than } \\
\text { once a week }\end{array}$ & 6925 & 11.4 & 89.0 & \\
\hline $\begin{array}{l}\text { At least once } \\
\text { a week }\end{array}$ & 15065 & 24.7 & 93.0 & \\
\hline \multicolumn{4}{|l|}{ Religion } & $<0.001$ \\
\hline No religion & 565 & 0.9 & 80.2 & \\
\hline Christianity & 16269 & 26.7 & 855.0 & \\
\hline Islam & 9363 & 15.4 & 73.8 & \\
\hline Traditionalist & 33904 & 55.6 & 89.1 & \\
\hline Others & 863 & 1.4 & 86.1 & \\
\hline \multicolumn{4}{|c|}{ Community literacy level } & $<0.001$ \\
\hline Low & 24727 & 40.5 & 79.1 & \\
\hline Medium & 17294 & 28.4 & 88.0 & \\
\hline High & 18943 & 31.1 & 91.9 & \\
\hline \multicolumn{4}{|c|}{ Community socioeconomic status } & $<0.001$ \\
\hline Low & 40821 & 67.0 & 82.3 & \\
\hline Medium & 2217 & 3.6 & 87.1 & \\
\hline High & 17926 & 29.4 & 92.7 & \\
\hline \multicolumn{4}{|c|}{ Place of residence } & $<0.001$ \\
\hline Rural & 19063 & 31.3 & 92.7 & \\
\hline Urban & 41901 & 68.7 & 82.3 & \\
\hline
\end{tabular}

${ }^{*} \mathrm{P}$ values obtained from $\mathrm{X}^{2}$ test.

ANC, antenatal care; PNC, postnatal care.

childhood vaccination was mostly found in women who had normal delivery $(95.4 \%)$, mothers aged $20-24$ $(86.3 \%)$, never married $(91.0 \%)$, working $(87.2 \%)$ and affiliated to traditional religion $(89.1 \%)$. In the area of mass media, women who read the newspapers less than once a week $(94.9 \%)$, listened to the radio at least once a week $(91.1 \%)$ and watched television at least once a week $(93.0 \%)$ had the highest prevalence of complete vaccination. Regarding community-level factors, complete 
vaccination was highest among children from communities with a high level of education $(91.9 \%)$, high socioeconomic status $(92.7 \%)$ and residing in rural areas $(92.7 \%)$. Results from the $\mathrm{X}^{2}$ analysis showed that all the maternal healthcare service utilisation factors were associated with complete childhood vaccination. Also, all the child and maternal and community-level factors were associated with complete vaccination except for twin status. All the associated variables had $\mathrm{p}<0.001$.

\section{Maternal healthcare utilisation and control variables associated with complete childhood vaccination}

Table 4 shows the results of the association between maternal healthcare service utilisation and complete childhood vaccination. In the complete model (model 4 ), children whose mothers had a maximum of three ANC attendance $(\mathrm{aOR}=0.44,95 \%$ CI 0.42 to 0.46$)$ were $56 \%$ less likely to have complete vaccination, compared with those who had at least four ANC visits $(\mathrm{aOR}=0.44$, 95\% CI 0.42 to 0.46 ). We found that children whose mothers had assisted delivery by traditional birth attendant/other ( $\mathrm{aOR}=0.43,95 \%$ CI 0.41 to 0.56$)$ had lower odds of receiving complete vaccination. Also, the odds of complete immunisation were lower among children whose mothers did not attend PNC clinics $(\mathrm{aOR}=0.26$, 95\% CI 0.24 to 0.29 ) as against those whose mothers attended. The lowest odds of complete vaccination were found among children with smaller than average birth size, $5+$ birth order children, children delivered through vaginal birth, children born to mothers aged 15-19, children born to non-working mothers, and children born to mothers who never read newspaper nor listened to radio. Similarly, the odds of complete vaccination were lowest among children born to mothers who belonged to 'other religion', those who lived in communities with low educational level and socioeconomic status and those who lived in urban areas.

\section{DISCUSSION}

We examined the association between maternal healthcare service utilisation and complete childhood vaccination. The association between other child and maternal and community-level factors and complete childhood vaccination was also examined. We found that mothers who had $<4$ ANC visits, those who were assisted by traditional birth attendant/other and mothers who did not attend PNC clinics were less likely to provide complete vaccination to their children. The lowest odds of complete vaccination were found among children with smaller than average birth size, $5+$ birth order children, children delivered through vaginal birth, children born to mothers aged 15-19, children born to non-working mothers, and children born to mothers who never read newspaper nor listened to radio. Similarly, the odds of complete vaccination were lowest among children born to mothers who belonged to 'other religion', those who lived in communities with low educational level and socioeconomic status and those who lived in urban areas.

Our finding on the association between ANC attendance and complete childhood vaccination is consistent with studies from Ethiopia, ${ }^{37}$ Nigeria, ${ }^{38}$ South Africa, ${ }^{39}$ Senegal $^{40}$ and Zimbabwe. ${ }^{41}$ In those studies, low ANC attendance was associated with lower odds of complete childhood vaccination. Similarly, Restrepo-Méndez et $a t^{42}$ found in low-income and middle-income countries that full vaccination coverage was lowest among children born to mothers who failed to attend ANC and highest among those whose mothers had four or more ANC visits. Several factors could explain the finding in this current study. First, women with more ANC visits may gain satisfaction with healthcare access and obtain accurate information on the importance of vaccination, which could lead to higher vaccination coverage. ${ }^{43}$ For instance, Ndwandwe $e t$ $a l^{p 9}$ stated that frequent ANC visits help women to build good rapport with healthcare providers, and such relationships create opportunities for healthcare providers to encourage and sensitise women to make healthcareseeking for themselves and their children a priority.

Our study found that the odds of complete vaccination were lower among children whose mothers had assisted delivery by TBA or others. This finding corroborates previous studies conducted in Ethiopia, ${ }^{44}{ }^{45}$ Senegal $^{40}$ and Zimbabwe, ${ }^{41}$ which found that children from women who delivered in a health facility were more likely to have complete vaccination. Similar findings were obtained in a study conducted in Nigeria. ${ }^{46}$ The observed correlation in the study could be explained that women who delivered at health facilities might have a high level of awareness and be more knowledgeable about their health and that of their children. ${ }^{47}$ Also, Mukungwa ${ }^{41}$ posited that women who deliver at health facilities are well informed about the benefits of complete vaccination. The result could imply that delivery at health facilities enables women to receive adequate training from health professionals on the importance of childhood vaccinations and this builds their confidence in using preventive health services. ${ }^{46}$

Also, our finding showed that children whose mothers did not attend PNC had lower odds of being vaccinated compared with those whose mothers attended more PNC. This result confirms the association between PNC attendance and full or complete childhood vaccination as found in several studies. ${ }^{33} 384247$ It seems possible that the results could be attributed to the fact that early PNC provides an avenue to initiate vaccines such as BCG, Diptheria, Pertussis and Tetanus (DPT) and polio, which could later enhance compliance with the immunisation programme and also an opportunity to initiate vaccination among those not immunised. ${ }^{47}$ Another possible explanation could be that during PNC, mothers are educated and counselled on the importance of immunising their children against vaccine-preventable diseases and deaths. ${ }^{33}$

Concerning childhood factors, complete vaccination was lower among children with birth size both larger and 
Table 4 Fixed and random effects results on the association between maternal healthcare services utilisation and complete childhood vaccination in sub-Saharan Africa

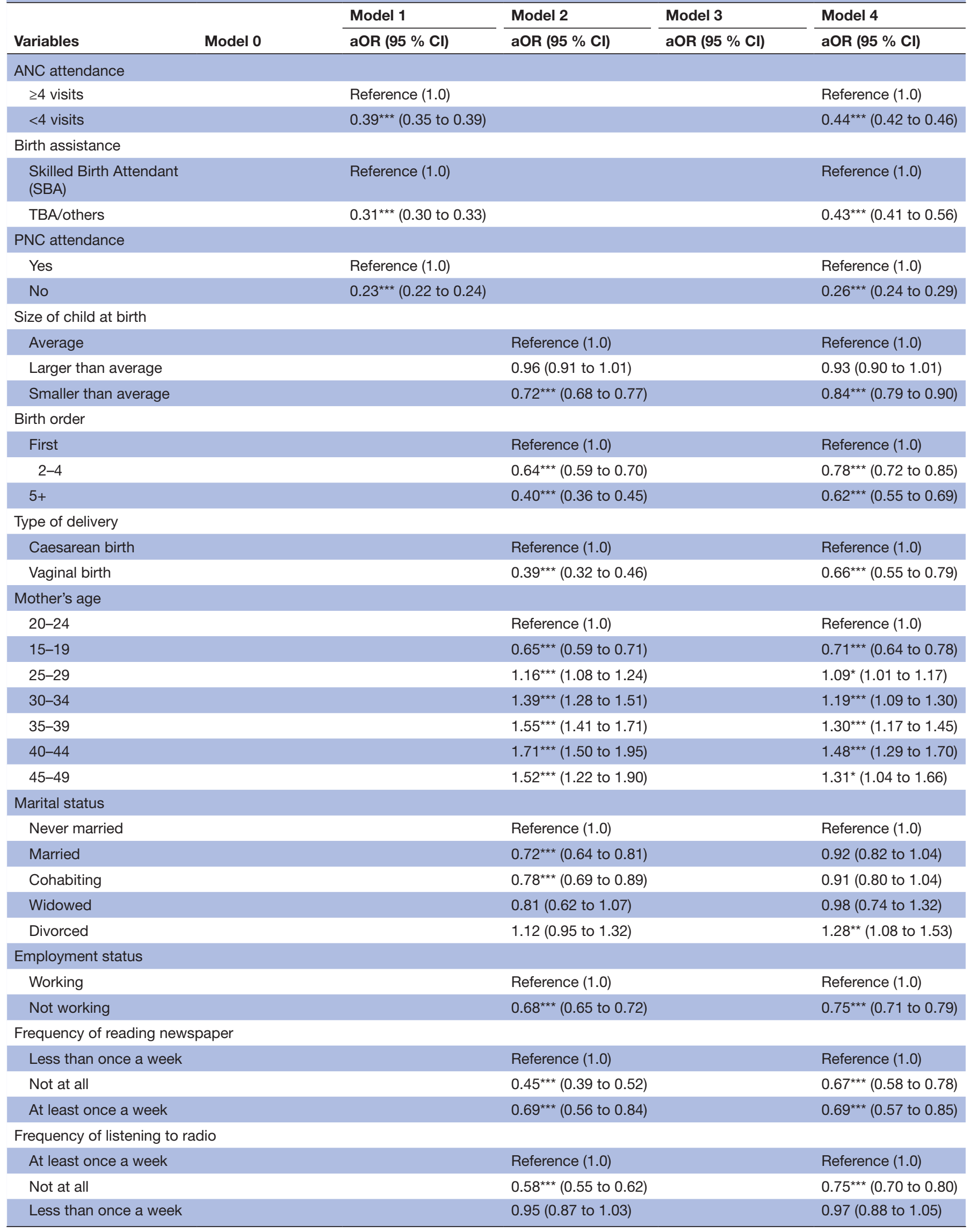


Table 4 Continued

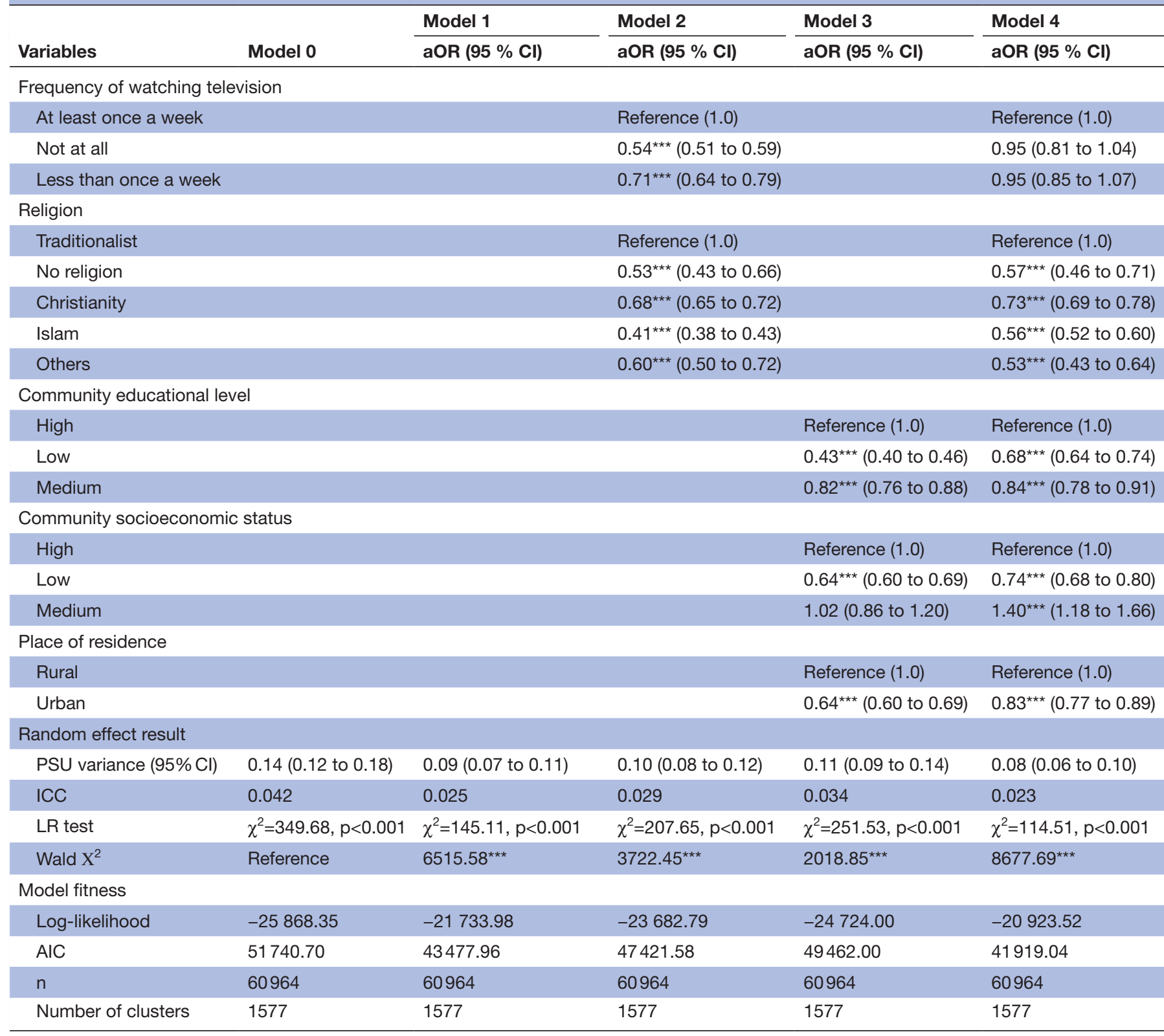

Exponentiated coefficients, $95 \% \mathrm{Cl}$ in brackets.

1.0=reference category.

${ }^{*} \mathrm{P}<0.05,{ }^{* *} \mathrm{P}<0.01,{ }^{* * *} \mathrm{P}<0.001$.

AIC, Akaike's information criterion; ANC, antenatal care; aOR, adjusted OR; ICC, intraclass correlation; LR Test, likelihood ratio test; PNC, postnatal care; PSU, primary sampling unit.

small than average compared with those with average size at birth. Compared with those with first birth order, children from second birth order and above had lower odds of complete vaccination. Per the present results on birth order, previous studies have demonstrated that the odds of complete immunisation decrease with increasing birth order. ${ }^{414}$ The result could be explained by the mother's reduced desire in immunisation uptake for children of higher birth order. ${ }^{44}$ In explaining the association between birth order and complete vaccination, Kawakatsu and Honda ${ }^{48}$ stated that the larger the family size, the greater the resource utilisation, and this could become problematic especially for families in resource-poor setting, and this subsequently influences their livelihood in which health-seeking behaviour could be a component. With size at birth, children born with low birth weight had lower odds of complete childhood vaccination. This could be attributed to the fragile belief in respect to small children as most parents often consider them too fragile for immunisation. ${ }^{44}$ Also, the lower odds of vaccination with larger birth size could be due to large size often being perceived as a sign of good health and this can influence their immunisationseeking behaviour. 
We found that maternal characteristics such as divorce, not working, less exposure to mass media, not having a normal delivery and being affiliated to other religious bodies aside from the traditional religion were associated with lower odds of complete childhood vaccination. On the other hand, complete vaccination increased with higher maternal age. The results confirm those of other studies which found consistent associations between maternal characteristics and childhood vaccination. ${ }^{41464950}$ As found in other studies, ${ }^{33} 4146$ exposure to mass media should be emphasised due to its significant positive association with complete vaccination. As a result, well-crafted and tailored information and sensitisation programmes and messages should be disseminated through radio stations, newspapers and television stations based on the positive outcomes from other studies. ${ }^{46} 51$ Also, higher likelihood of complete childhood vaccination with increasing age could be explained using the assertion that the level of experience and knowledge on the importance of immunisation increases over time, and cues from health complications resulting from not immunising a child could account for the observed association and hence the need for further education and sensitisation on vaccination. ${ }^{51}$ With respect to the results on the religious affiliation in this current study, Costa $e t$ $a \tilde{l}^{2}$ argued that the coverage of vaccination increases with the involvement of religious leaders and this is in line with the leave-no-one-behind agenda of the SDGs. Thus, religious leaders should be involved in the sensitisation, education and delivery of immunisation information. A study in Nigeria concluded that inherit cultural beliefs underpinning vaccination mistrust could be the reason for the negative association found in the study. ${ }^{50}$

At the community level, our finding showed that the odds of complete vaccination were low for children residing in urban areas, living in communities with low socioeconomic status, and low and medium educational levels. However, children from communities with medium socioeconomic status were more likely to be completely vaccinated. The association between socioeconomic status and complete vaccination supports works from other studies which assert that high socioeconomic status (education and wealth) increases the likelihood of childhood vaccination. ${ }^{4344650}$ As stated in Adedokun et $a l^{46}$ the socioeconomic status of the community influences the health-seeking behaviour of individuals, which could explain the observed association in the study where children from communities with socioeconomic status above medium and high educational level increased the odds of complete vaccination. In explaining the interaction between education and wealth, Kawakatsu and Honda ${ }^{48}$ posited that the interaction is disordinal such that the effect of literacy depends on the wealth index; thus, literacy is significantly related to full vaccination in the context of the rich or richest. The authors further revealed that literacy among wealthy households enables them to better access health-related information provided by the mass media and health professionals.

\section{Strengths and limitations}

The strength of the study lies in the use of regionally representative data from SSA countries that used a multistage sampling technique to recruit the study respondents. The results could be generalised to all children aged 11-23 months in the SSA. The study comes with limitations. First of all, the cross-sectional nature of the study makes it difficult to establish a causal relationship between complete childhood vaccination and explanatory variables. Second, the use of verbal responses to ascertain vaccination coverage could be prone to potential recall bias. Also, due to the secondary data used, the study could not use health system factors such as poor scheduling of vaccination days, shortage of vaccines and logistics, and long waiting periods, which could impact the observed association in our study. Moreover, the findings should be interpreted carefully due to variations in country-specific factors such as socioeconomic factors, healthcare system distribution and accessibility, cultural belief, geographical inequalities, and delivery of vaccination activities. Finally, in terms of $X^{2}$ test, some of the variables had more than two groups, which made the use of $X^{2}$ test less efficient to provide enough information to understand the nature of the relationship between those variables and the outcome variable.

\section{CONCLUSION}

This study has shown that children whose mothers had $<4$ ANC visits, delivered with assistance from TBA/others and no PNC were less likely to vaccinate their children completely. The empirical findings in this study provide evidence on the association between maternal healthcare utilisation and childhood vaccination. Findings from the study therefore call for the development and implementation of interventions aimed at improving maternal healthcare utilisation. Comprehensive strategies used in delivering immunisation should encompass counselling and education on the benefits of vaccination. This will aid in achieving SDG 3 target 3.2.

\section{Author affiliations \\ ${ }^{1}$ Department of Population and Health, University of Cape Coast, Cape Coast, Ghana ${ }^{2}$ Faculty of Health, The Australian Centre for Public and Population Health Research, University of Technology Sydney, Sydney, New South Wales, Australia \\ ${ }^{3}$ School of Public Health, University of Health and Allied Sciences, Ho, Ghana \\ ${ }^{4}$ College of Public Health, Medical and Veterinary Sciences, James Cook University, Townsville, Queensland, Australia \\ ${ }^{5}$ Department of Health Promotion, and Disability Studies, Kwame Nkrumah University of Science and Technology, Kumasi, Ghana \\ ${ }^{6}$ School of International Development and Global Studies, University of Ottawa, Ottawa, Ontario, Canada \\ ${ }^{7}$ The George Institute for Global Health, Imperial College London, London, UK}

Acknowledgements The authors thank the MEASURE DHS project for their support and free access to the original data.

Contributors EB, SY and BOA contributed to the study design and conceptualisation. EB and BOA performed the analysis. RGA, EKA-A, A-AS and $C A$ reviewed the literature. EB, BOA, RGA, EKA-A, A-AS, CA, EKA and SY provided technical support and critically reviewed the manuscript for its intellectual content. 
SY had final responsibility to submit for publication. All authors read and amended drafts of the paper and approved the final version.

Funding The authors have not declared a specific grant for this research from any funding agency in the public, commercial or not-for-profit sectors.

Competing interests None declared.

Patient consent for publication Not required.

Ethics approval Ethics approval was not required for this study since the data are secondary and are available in the public domain. More details regarding DHS data and ethical standards are available at http://goo.gl/ny8T6X. The ethics committee of ORC Macro as well as the ethics boards of partner organisations of the various countries such as the ministries of health provided ethics approval for the surveys. The DHS follows the standards for ensuring the protection of respondents' privacy. ICF International ensures that the survey complies with the US Department of Health and Human Services' regulations for the respect of human subjects. Since, the DHS is a secondary data that are available in the public domain, no further approval was required from the authors to use the data. However, we sought and obtained permission from MEASURE DHS to use the data. Further information about the DHS data usage and ethical standards are available at http://goo.gl/ny8T6X.

Provenance and peer review Not commissioned; externally peer reviewed.

Data availability statement Data are available in a public, open access repository. Data for this study were sourced from Demographic and Health Surveys (DHS) and available at http://dhsprogram.com/data/available-datasets.cfm.

Supplemental material This content has been supplied by the author(s). It has not been vetted by BMJ Publishing Group Limited (BMJ) and may not have been peer-reviewed. Any opinions or recommendations discussed are solely those of the author(s) and are not endorsed by BMJ. BMJ disclaims all liability and responsibility arising from any reliance placed on the content. Where the content includes any translated material, BMJ does not warrant the accuracy and reliability of the translations (including but not limited to local regulations, clinical guidelines, terminology, drug names and drug dosages), and is not responsible for any error and/or omissions arising from translation and adaptation or otherwise.

Open access This is an open access article distributed in accordance with the Creative Commons Attribution Non Commercial (CC BY-NC 4.0) license, which permits others to distribute, remix, adapt, build upon this work non-commercially, and license their derivative works on different terms, provided the original work is properly cited, appropriate credit is given, any changes made indicated, and the use is non-commercial. See: http://creativecommons.org/licenses/by-nc/4.0/.

\section{ORCID iDs}

Bright Opoku Ahinkorah http://orcid.org/0000-0001-7415-895X

Abdul-Aziz Seidu http://orcid.org/0000-0001-9734-9054

Sanni Yaya http://orcid.org/0000-0002-4876-6043

\section{REFERENCES}

1 Zhao P, Han X, You L, et al. Maternal health services utilization and maternal mortality in China: a longitudinal study from 2009 to 2016 . BMC Pregnancy Childbirth 2020;20:1-10.

2 Zamawe COF, Banda M, Dube AN. The impact of a community driven mass media campaign on the utilisation of maternal health care services in rural Malawi. BMC Pregnancy Childbirth 2016;16:21.

3 Garenne M. Maternal mortality in Africa: investigating more, acting more. Lancet Glob Health 2015;3:e346-7.

4 Ghose B, Feng D, Tang S, et al. Women's decision-making autonomy and utilisation of maternal healthcare services: results from the Bangladesh Demographic and Health Survey. BMJ Open 2017;7:e017142.

5 , et alWHO, UNICEF, UNFPA. Maternal mortality: levels and trends 2000 to $2017,2019$.

6 Nuamah GB, Agyei-Baffour P, Mensah KA, et al. Access and utilization of maternal healthcare in a rural district in the forest belt of Ghana. BMC Pregnancy Childbirth 2019;19:6.

7 WHO. Respectful maternity care the universal rights of childbearing women, 2015. http://www.who.int/woman_child_accountability/ ierg/reports/2012_01S_Respectful_Maternity_Care_Charter_The_ Universal_Rights_of_Childbearing_Women.pdf

8 Asuman D, Ackah CG, Enemark U. Inequalities in child immunization coverage in Ghana: evidence from a decomposition analysis. Health Econ Rev 2018;8:9.

9 WHO. Global immunization coverage sustained in the past five years 2016. Available: http://www.who.int/immunization/ newsroom/press/ immunization_coverage_july_2016/en/ [Accessed 10 Oct 2020].
10 Akwataghibe NN, Ogunsola EA, Broerse JEW, et al. Exploring factors influencing immunization utilization in Nigeria-A mixed methods study. Front Public Health 2019;7:392.

11 Machingaidze S, Wiysonge CS, Hussey GD. Strengthening the expanded programme on immunization in Africa: looking beyond 2015. PLoS Med 2013;10:e1001405.

$12 \mathrm{Kc} \mathrm{A}$, Nelin V, Raaijmakers $\mathrm{H}$, et al. Increased immunization coverage addresses the equity gap in Nepal. Bull World Health Organ 2017;95:261.

13 Oyo-Ita A, Wiysonge CS, Oringanje C, et al. Interventions for improving coverage of childhood immunisation in low- and middleincome countries. Cochrane Database Syst Rev 2016;9.

14 Kassebaum NJ, Barber RM, Bhutta ZA, et al. Global, regional, and national levels of maternal mortality, 1990-2015: a systematic analysis for the global burden of disease study 2015. Lancet 2016;388:1775-812.

15 Campbell OMR, Graham WJ. Lancet maternal survival series steering G. strategies for reducing maternal mortality: getting on with what works. Lancet 2006;368:1284-99.

16 Austin A, Langer A, Salam RA, et al. Approaches to improve the quality of maternal and newborn health care: an overview of the evidence. Reprod Health 2014;11:S1.

17 WHO. Newborns: improving survival and well-being, 2020

18 Amouzou A, Ziqi M, Carvajal-Aguirre L, et al. Skilled attendant at birth and newborn survival in Sub-Saharan Africa. J Glob Health 2017;7.

19 Dahiru T. Determinants of early neonatal mortality in Nigeria: results from 2013 Nigeria DHS. J Pediatr Neonatal Care 2015;2:00089.

20 Bhutta ZA, Cabral S, Chan C-W, et al. Reducing maternal, newborn, and infant mortality globally: an integrated action agenda. Int $J$ Gynaecol Obstet 2012;119:S13-17.

21 Bryce J, Terreri N, Victora CG, et al. Countdown to 2015: tracking intervention coverage for child survival. Lancet 2006;368:1067-76.

22 Mihigo R, Anya B, Okeibunor J. Routine immunization in the WHO African region: progress, challenges and way forward. African Health Monitor 2015;19:2-4.

23 Mbengue MAS, Mboup A, Ly ID, et al. Vaccination coverage and immunization timeliness among children aged 12-23 months in Senegal: a Kaplan-Meier and COX regression analysis approach. Pan Afr Med J 2017;27:8.

24 Corsi DJ, Neuman M, Finlay JE, et al. Demographic and health surveys: a profile. Int J Epidemiol 2012;41:1602-13.

25 Aliaga A, Ren R. Optimal sample sizes for two-stage cluster sampling in demographic and health surveys. Calverton: Maryland ORC Macro MEASURE, 2006.

26 von Elm E, Altman DG, Egger M, et al. The strengthening the reporting of observational studies in epidemiology (STROBE) statement: guidelines for reporting observational studies. Int J Surg 2014;12:1495-9.

27 WHO. Immunization schedules - Africa, 2018.

28 Ameyaw EK, Kareem YO, Ahinkorah BO, et al. Decomposing the rural-urban gap in factors associated with childhood immunisation in sub-Saharan Africa: evidence from surveys in 23 countries. BMJ Glob Health 2021;6:e003773.

29 Budu E, Seidu A-A, Agbaglo E. Maternal healthcare utilization and full immunization coverage among 12-23 months children in Benin a cross sectional study using population-based data. Archives of Public Health 2021;79:1-12.

30 Tefera YA, Wagner AL, Mekonen EB, et al. Predictors and barriers to full vaccination among children in Ethiopia. Vaccines 2018;6:22

31 Yismaw AE, Assimamaw NT, Bayu NH, et al. Incomplete childhood vaccination and associated factors among children aged 1223 months in Gondar city administration, Northwest, Ethiopia 2018. BMC Res Notes 2019;12:241.

32 Canavan ME, Sipsma HL, Kassie GM, et al. Correlates of complete childhood vaccination in East African countries. PLoS One 2014;9:e95709.

33 Budu E, Darteh EKM, Ahinkorah BO, et al. Trend and determinants of complete vaccination coverage among children aged 12-23 months in Ghana: analysis of data from the 1998 to 2014 Ghana demographic and health surveys. PLoS One 2020;15:e0239754.

34 Budu E, Seidu A-A, Opoku Ahinkorah B, et al. Determinants of complete immunizations coverage among children aged 12-23 months in Papua New Guinea. Child Youth Serv Rev 2020;118:105394.

35 Austin PC, Merlo J. Intermediate and advanced topics in multilevel logistic regression analysis. Stat Med 2017;36:3257-77.

36 Merlo J, Wagner P, Ghith N, et al. An original stepwise multilevel logistic regression analysis of discriminatory accuracy: the case of neighbourhoods and health. PLoS One 2016;11:e0153778. 
37 Debie A, Lakew AM, Tamirat KS, et al. Complete vaccination service utilization inequalities among children aged 12-23 months in Ethiopia: a multivariate decomposition analyses. Int $J$ Equity Health 2020;19:1-16.

38 Anichukwu OI, Asamoah BO. The impact of maternal health care utilisation on routine immunisation coverage of children in Nigeria: a cross-sectional study. BMJ Open 2019;9:e026324.

39 Ndwandwe D, Nnaji CA, Mashunye T. Incomplete vaccination and associated factors among children aged 12-23 months in South Africa: an analysis of the South African demographic and health survey 2016. Human Vaccines Immunotherapeutics 2020:1-8.

40 Mbengue MAS, Sarr M, Faye A, et al. Determinants of complete immunization among senegalese children aged 12-23 months: evidence from the demographic and health survey. BMC Public Health 2017:17:630.

41 Mukungwa T. Factors associated with full immunization coverage amongst children aged 12-23 months in Zimbabwe. African Population Stud 2015;29.

42 Restrepo-Méndez MC, Barros AJ, Wong KL, et al. Inequalities in full immunization coverage: trends in low- and middle-income countries. Bull World Health Organ 2016;94:794.

43 Ntenda PAM. Factors associated with non- and under-vaccination among children aged 12-23 months in Malawi. A multinomial analysis of the population-based sample. Pediatr Neonatol 2019;60:623-33.

44 Moyer CA, Tadesse L, Fisseha S. The relationship between facility delivery and infant immunization in Ethiopia. Int J Gynaecol Obstet 2013;123:217-20.
45 Abadura SA, Lerebo WT, Kulkarni U, et al. Individual and community level determinants of childhood full immunization in Ethiopia: a multilevel analysis. BMC Public Health 2015;15:972.

46 Adedokun ST, Uthman OA, Adekanmbi VT, et al. Incomplete childhood immunization in Nigeria: a multilevel analysis of individual and contextual factors. BMC Public Health 2017;17:236.

47 Acharya P, Kismul H, Mapatano MA, et al. Individual- and community-level determinants of child immunization in the Democratic Republic of Congo: a multilevel analysis. PLoS One 2018;13:e0202742.

48 Kawakatsu Y, Honda S. Individual-, family- and community-level determinants of full vaccination coverage among children aged 1223 months in Western Kenya. Vaccine 2012;30:7588-93.

49 Adokiya MN, Baguune B, Ndago JA. Evaluation of immunization coverage and its associated factors among children 12-23 months of age in Techiman Municipality, Ghana, 2016. Arch Public Health 2017;75:28

50 Olorunsaiye CZ, Degge $\mathrm{H}$. Variations in the uptake of routine immunization in Nigeria: examining determinants of inequitable access. Glob Health Commun 2016;2:19-29.

51 Bbaale E. Factors influencing childhood immunization in Uganda. $J$ Health Popul Nutr 2013;31:118.

52 Costa JC, Weber AM, Darmstadt GL, et al. Religious affiliation and immunization coverage in 15 countries in sub-Saharan Africa. Vaccine 2020;38:1160-9. 